\title{
How not to think about the ethics of deceiving into $\operatorname{sex}^{1}$
}

Where sexual relations are concerned, our communication often fails to adhere to the highest standards of honesty and integrity. ${ }^{2}$ Prowess and status may be exaggerated, false expressions of emotion made, and commitments undertaken without full sincerity. We tolerate many kinds of misleading acts, aimed at securing sexual consent. But not all deceptive procurement of sexual consent is innocent. For example, impersonation of a person's spouse or partner by way of procuring sex is both morally wrong and legally prohibited.

It is important to note that some, perhaps a great deal, of deceptive communication, in the context of sexual relations, may make no difference to the decision to consent. In other situations deception conceals a fact—a "dealbreaker"—such that were the victim to have known of that fact she would not have consented. Tom Dougherty has argued that whenever one party $\mathrm{S}$ deceives another party $\mathrm{R}$ into sex, by concealing a dealbreaker, the normative situation is the same as there being no morally valid consent at all for that act, by that person. ${ }^{3}$ As such, deception into sex wrongs the victim in the same way as sex with the victim whilst comatose. ${ }^{4}$ Importantly, he argues that this is the case even if the deception is

\footnotetext{
${ }^{1}$ I would like to thank two anonymous referees for their very helpful observations, criticisms, and positive suggestions, the paper is much improved thanks to their attention and care. I would also like to thank Tom Dougherty for discussing some of the matters discussed below and for his thorough, careful, work in the philosophy of consent. Although I argue here against his particular account of the ethics of deception into sex we do agree upon a great deal about the nature of consent and its normative significance.

${ }^{2}$ Hancock, Jeffrey T., Catalina Toma, and Nicole Ellison. 'The truth about lying in online dating profiles.' Proceedings of the SIGCHI conference on Human factors in computing systems. ACM, 2007.

${ }^{3}$ Dougherty, Tom. 'Sex, Lies, and Consent*.' Ethics 123.4 (2013): 717-744. References to this are placed in main body text.

${ }^{4}$ As Dougherty puts it ' we can clarify the seriousness of the wrong in question by noting its commonalities with sex with an unwilling comatose person' (721). Deception into sex may wrong the 'dupe' in a wide variety of ways (e.g., by breaching trust, undermining valuable relationships, or, in the case of failure to disclose risks posed by sex, the wrongs attendant on harming the consentor, and there are further contrasts between sex with a waking person and a comatose one. The focus here is upon the way that deception invalidates consent, so our discussion is restricted to the wrongings that are set aside by consent and upon the question whether Dougherty
} 
about what may seem to be a trivial or minor matter such as income or educational history. Dougherty thus sets himself against orthodox intuitions about sexual consent. Such orthodoxy is committed to the Lenient Thesis: 'It is only a minor wrong to deceive another person into sex by misleading her or him about certain personal features such as natural hair color, occupation, or romantic intentions' (718).

Some clarifications are needed here. First, if our view of the ethics of deception is that deception is never a minor wrong, then we might reject the Lenient Thesis as stated but still agree with the widespread view that deception about one's taste in pets, the context of sexual consent, wrongs the duped party less than complete concealment of the performance of a sexual act. The Lenient Thesis is meant to articulate a widespread view that deceiving about different kinds of things, such that the 'dupe' is deceived into sex, involves varying degrees of wronging. As Dougherty puts it 'most people think that the wrongness depends on the type of deception involved. Impersonating someone's spouse is seriously wrong but not so with runof-the-mill falsehoods like "I'm not fussed about mess"' (718). Dougherty's view is that deceiving someone into sex by lying about, or concealing, one's pet preferences wrongs the duped party in the same way that sex with them whilst comatose would (721), for, in each case, in Dougherty's view, there is no morally valid consent to sex.

The Lenient Thesis can be interpreted in different ways. On one reading-an objective reading - the Lenient Thesis reflects the view that there is: (a) a class of facts A, such that deception into sex that induces false beliefs about members of A does seriously wrong the victim (e.g., A would include facts about identity, or about one's performing a sexual act in place of a medical examination); (b) a second class of facts $B$, such that deception about these

is right that deception into sex by concealing, or inducing false beliefs about what may seem to be 'trivial' matters invalidates consent in the same way that deception about identity, or about the fact that one is performing a sexual act (rather than, say, a medical examination) undermines consent. There are further distinctions to be drawn within all these classes of deceptively procured consent. 
facts may wrong the dupe, but not in the way that deception about members of A does. We shall see below that Dougherty assumes that what 'most people think' is this objective variant (see the section below dealing with the distinction between core and peripheral aspects of the sexual act). But this is not the only way of articulating our intuitions about leniency. For example, we might plausibly reject the idea that there is a normative difference between the two objective classes of facts $\mathrm{A}$ and $\mathrm{B}$ as noted above, whilst holding that in the main people will tend to care more about some things rather than others. On this "subjective" variant of the Lenient Thesis deception about pet preferences, or which school one attended, is less apt to invalidate consent because - and we shall expand on this below-such facts, for most people, will tend to be less important.

However we interpret the Lenient Thesis, Dougherty's arguments entail that there is much more nonconsensual sex than we currently think (even if there are methodological problems in determining just how much more. On his expansionist account of the deceptive undermining of consent, many of us have been, or will be, guilty of wronging others in an extremely serious way: in fact, in just the same way that we would were we to have sex with someone whilst comatose. Similarly, many more of us than we ordinarily think will be (or have been) seriously wronged by others. If this expansionist theory of is correct, then further questions arise about the extent to which, and the ways in which, we ought to revise our sexual mores, and, if necessary, our laws about fraudulently procured sex.

There would be little problem if his expansionist conclusion were clearly unsupported. But Dougherty has a number of interconnected, well-developed and plausible arguments, both positive (in favour of his expansion of serious wrongings) and negative (against alternative theories of deceptive undermining of consent that are consistent with the Lenient Thesis). A 
false, but seemingly plausible, theory that provides grounds for (mistakenly) accusing countless people of serious wrongdoing is not a good thing to have accepted as common knowledge. Although Dougherty's arguments are plausible, they are not sound: we should not think about the deceptive undermining of sexual consent in the way that the expansionist account demands.

Because Dougherty's arguments are complex and multi-faceted, it will take a little time to unpack what is going on, and to show where things goes wrong. The shape of the discussion is this. In the first section we introduce a theory of the deceptive undermining of consentthe "gradable voluntariness theory" — that is consistent with, and lends indirect support to, the Lenient Thesis. Section two examines Dougherty's three lines of argument against this theory and finds them wanting, particularly because he fails to acknowledge that 'dealbreakers' can be stronger or weaker (and we shall explain what we mean by this below). Sections three and four critically examine two positive lines of argument that Dougherty offers (lines of argument that have a degree of independence from the negative arguments discussed in section two). But each of these positive lines of argument is problematic. Our conclusion will be that Dougherty's arguments against the Lenient Thesis fail (his negative arguments leave the "subjective" variant standing, whilst the flaws in his positive arguments leave both the "subjective" and "objective" variants untouched.

\section{The 'gradable voluntariness' theory}

The Lenient Thesis receives support from extant theorizing about the ethics of deception into sex. Many theorists of sexual consent advocate variants of what Dougherty calls the gradable voluntariness theory of how deception undermines consent: if deception leads a person to make a consent decision that they would not have done, then, in some 
circumstances such deception invalidates the consent so given. ${ }^{5}$ The starting point for this theory is the recognition that voluntariness is a necessary condition for valid consent. An act of consent is morally efficacious (valid) only if it is properly voluntary. An act of consent procured at gunpoint is not valid and the normative situation is not changed in the way that it is by a valid act of consent. Just as coercion can restrict or impinge upon voluntariness, so too can deception. Joan McGregor, for example, suggests that 'deception or fraud, similarly to coercion, affects the voluntariness of an agent's action' adding that it thus 'undermin[es] the legitimacy of consent'. ${ }^{6}$

It is important to note that the gradable voluntariness theory recognises that deception can influence another's decision to a greater or lesser degree. As Feinberg puts it, there is 'a spectrum of voluntariness, [ . . .], corresponding to variations in the fraudulently produced inducement to consent, just as there seems to be a spectrum of voluntariness corresponding to degrees of coercive pressure'. ${ }^{7}$ Coercion lies at one end of a continuum of degrees of (undue) influence. In a similar way, the gradable voluntariness account can hold that deception can impinge upon an agent's decision-making to a greater or lesser degree. As Archard puts it, a person who is deceived into sex 'is wronged to the extent that her will is not implicated in the [sexual] act and it does not express her free choices'. ${ }^{8}$

The gradable voluntariness theory takes into account the fact that some kinds of deception may merely tip the balance in favour of deciding to consent. Where deception tips the balance the relevant counterfactual — if $\mathrm{R}$ were to know that $p$ she would not consent - is true,

\footnotetext{
${ }^{5}$ Variants of the gradable voluntariness theory are endorsed by, amongst others, Joel Feinberg 'Victims' excuses: The case of fraudulently procured consent.' Ethics (1986): 330-345; Peter Westen. The logic of consent. Ashgate, 2004 (e.g., p. 188); Jonathan Hering, 'Mistaken Sex,' Criminal Law Review (2005):511-524; D. Archard, Sexual consent. Westview Press, 1998.

${ }^{6}$ J. McGregor, Is it Rape? On Acquaintance Rape and Taking Women's Consent Seriously (2005) p.181. In a similar way Estrich, Susan Estrich claims that 'the 'force' or 'coercion' that negates consent ought be defined to include extortionate threats and deceptions of material fact' . 'Rape'. The Yale Law Journal 95.6 (1986): 10871184. p. 1182

${ }^{7}$ Feinberg, op. cit. p. 335

${ }^{8}$ Archard op.cit. p. 49
} 
but the counterfactual is only made true by a relatively small set of very close possible worlds. Suppose R wouldn't want to have sex with older men. S, aware of this, dyes his hair to appear younger. Suppose R finds S attractive, witty, sexy. R willingly has sex with S. There are some close possible worlds where R knows the facts about S's age and does not consent. But there are also close possible worlds where $\mathrm{R}$ knows the facts and does consent (she might, for example, revise her extant preferences in light of new information "Who knew? Not all old guys are monsters!").

But deception can also lead the consentor to make a "never in a million years" type of decision. Suppose $\mathrm{S}$ deceives a devoutly religious $\mathrm{R}-$ who would rather die than have sex with a person outside her religion — into having sex, by lying about his religion. Even if $\mathrm{R}$ has other reasons for consenting to sex with $\mathrm{R}$, there are no close possible worlds where $\mathrm{R}$ knows the truth about S's religion and R consents. In this example, unlike the one above, we have a fantastically strong deal breaker.

The gradable voluntariness theory differs from Dougherty's theory in the following way: Dougherty argues that whenever someone is deceived into consenting to sex the consent is morally invalid. The gradable voluntariness theory, by way of contrast, armed with a distinction between weak and strong deal-breakers holds that not all deception into consent to sex invalidates the consent so given. On the theory favoured by Archard, just as coercion lies at one end of a continuum of influence, and undermines voluntariness, not all deception into sex undermines voluntariness to such a degree that the normative force of consent is undermined. Clearly there is a challenge here to identity the proper threshold - to specify how strong a dealbreaker needs to be to undermine the force of consent - but an analogous problem arises for the coercive undermining of consent too. 
For our purposes, what matters is that the gradable voluntariness theory offers an indirect line of support for the Lenient Thesis. We say "indirect" because, as we shall see in a moment, the gradable voluntariness does not imply that there is some special class of facts-e.g., facts about hair color, or occupation-such that deception about those facts does not invalidate consent whilst deception about other facts (about identity or religious faith, say) does invalidate consent. The gradable voluntariness theory holds that not all deception into consent invalidates consent. Only those deceptions that misdirect a consentor's decision to a particularly high degree do so: those that involve strong dealbreakers. However, it is not implausible to assume that for many, perhaps most, people facts about hair color or occupation are ones which are weighed up in the balance (that is, they will tend to feature in 'weak' dealbreakers) whilst facts about identity will tend to involve strong dealbreakers. If this assumption is correct then the graded voluntariness theory can explain why the Lenient Thesis holds.

There is scope here, of course, for disagreement about what our current intuitions to with 'leniency' actually are. We might reject Dougherty's Lenient Thesis, but argue that our intuitions about leniency in the domain of sexual consent are underpinned by something similar to, but not identical to, Dougherty's version. We might, for example, have some kind of qualified variant of the Lenient Thesis which holds that in the main deception about hair color does not invalidate consent (because, in the main it involves weak dealbreakers), whilst allowing that such deception may do so in some contexts (if, for that agent facts about hair color are a strong dealbreaker). This qualified version of the Lenient Thesis is distinct from Dougherty's own position because Dougherty's position does not allow for, or acknowledge, a distinction within the class of dealbreakers between strong and weak.

In sum, the gradable voluntariness theory accepts a distinction between strong and weak dealbreakers and, as such, it opens up the conceptual space to allow that some instances of 
deceiving into sex invalidate consent whilst others do not, which, in turn, offers an explanation of and support for a subjective variant of the Lenient Thesis. This kind of gradable view of the normative implications of deceiving into consent to sex is not open to Dougherty for whom any deception-by-dealbreaker invalidates consent.

\section{Three arguments against the gradable voluntariness theory (and why they fail)}

Dougherty has three lines of argument against the gradable voluntariness approach. First, he argues that it is internally inconsistent. Archard, a proponent of the gradable approach, notes that morally valid consent does not require the consentor to know everything about a sexual act or the agent performing it. For example, suppose $\mathrm{S}$ has $140 \mathrm{~g}$ of potassium in his body; R can consent to sex with a person with $140 \mathrm{~g}$ in their body without knowing that this is so. So what information does the consentor need to know? Archard suggests: 'only everything that would make a real difference to whether or not she consented'. ${ }^{9}$ Dougherty then objects:

This claim is in tension with the gradable voluntariness approach since the claim implies that all forms of deceiving someone into sex are nonconsensual. This is because ignorance of any deal-breaker makes 'a real difference to whether or not' one consents. So if false proclamations of love lead to someone being deceived into sex, then she does not validly consent. Her will is opposed to the encounter, given it is an encounter with someone who does not love her, and this is enough to make it the case that she does not validly consent. (728)

But this line of objection fails to distinguish two different lines of contrast. First, there is a contrast between irrelevant and relevant information. Second, once we are within the class of

\footnotetext{
${ }^{9}$ Archard, op. cit. p.46
} 
relevant information, any particular piece of information may make more or less of a difference, in that context, to R's decision. Consider the analogy with coercion. Suppose we ask: what kinds of things influence others? This would be a question about the 'entry condition' for influence. Things that fall outside this are of no influence at all. Then within the class of things that influence others there are grades of influence and, importantly, grades of undue influence with coercion at one end of the scale. Just because there is a binary contrast between relevance and irrelevance, does not imply that that there is no further normatively significant scalar contrast within the class of relevant items.

Dougherty has a second line of argument against the Lenient Thesis:

the Lenient Thesis can only plausibly be based on a(n) [ . . ] account of consent that makes a fundamental distinction between different features of a sexual encounter On this view, someone does not validly consent to a sexual encounter when deceived about its 'core' features, such as the interaction's not being a genuine medical procedure or the other person's not being one's usual romantic partner. When someone is misled about these core features, then her will is not sufficiently implicated in the act for it to be consensual. Someone may validly consent even when misled about the encounter's peripheral features, such as the other person's natural hair color, occupation, or romantic intentions. (728)

But Dougherty is mistaken to claim that the Lenient Thesis can only be based upon this kind of distinction. This is not what the gradable voluntariness theory is committed to, and, as we have seen, the gradable theory is consistent with the subjective variant of the Lenient Thesis. Whether or not some fact is a strong or weak dealbreaker for the consentor is a subjective matter in that is a function of the particular agent's preference set. Dougherty argues that the 
gradable theorist cannot draw upon this kind of subjective criterion of what matters whilst at the same time, endorsing the Lenient Thesis.

But if we take this line, then we should conclude that someone does not consent to sex when she is deceived into sex. For, by my stipulative definition, someone is deceived into sex when she forms a false belief about a deal breaker: the deception conceals a feature of the sexual encounter that makes a decisive difference to the victim's decision to have sex. (731)

But this just returns us to the mistake above: Dougherty does not seem to recognise, or allow, that dealbreakers themselves vary from weak to strong. In our "older man" example above, we have a weak dealbreaker (we don't have to "travel" far to find a possible world where $\mathrm{R}$ does know and consents); in the "religion" example we have a strong dealbreaker (only in very distant possible worlds does $\mathrm{R}$ know the facts about $\mathrm{S}$ 's religion and consent to sex). Dougherty then suggests:

to resist my claim that someone fails to consent whenever she is deceived into sex, someone would have to find a different way of drawing the distinction between subjectively core and peripheral features. I am doubtful that anyone could find a systematic way of drawing the distinction, let alone that she could adequately motivate this way of doing so. (732)

But this is exactly what the gradable voluntariness theory does provide, and in a way that mirrors issues about how coercion (in contrast to other kinds of influence) undermines consent. It will not seem to do so if we fail to recognise or acknowledge that misdirection 
comes in degrees, or if we ignore the fact that there is, in addition to the binary 'relevance/irrelevance' distinction, a distinction to be drawn amongst degrees of relevance.

We might conclude our response to Dougherty here: the gradable voluntariness theory is consistent with the subjective variant of the Lenient Thesis, and thus allows us to see why we might find it intuitive, but Dougherty gives us no good reason to reject the gradable voluntariness theory. But to stop here would be a mistake: for Dougherty has other positive lines of argument in favour of his expansionist conclusion. ${ }^{10}$

\section{Scope-based argument 1: the intentions thesis}

The gradable voluntariness theory focuses on the normative significance of unduly restricting or impinging upon the voluntariness of a decision to consent. But this is not the only way that a consent transaction can be "deficient" normatively speaking. Suppose R leaves a note in her kitchen addressed to her room-mate "Dear T, feel free to take my canoe this weekend." If some other party, $S$, secretly takes the canoe, $\mathrm{S}$ acts without R's consent. But the reason why $\mathrm{S}$ has no permission to act is not because $\mathrm{S}$ has impinged upon the voluntariness of R's decision to consent, $\mathrm{S}$ wrongs $\mathrm{R}$ here simply because $\mathrm{S}$ 's act falls outside the normative scope of R's consent. Now suppose that $\mathrm{S}$ wants to use R's canoe, but believes that $\mathrm{R}$ will not lend it to him. S then impersonates R's canoeing partner T and asks "May I take the canoe?" R's reply "of course" is intended to permit $\mathrm{T}$, not $\mathrm{S}$ to take the canoe. The consent that was given, did not permit $\mathrm{S}$ to take the canoe. There are examples of this kind involving consent to sex. Suppose $\mathrm{S}$ enters R's home late at night, and deceives $\mathrm{R}$ into thinking he is her husband T. She "consents" to sexual intercourse. Here R's consent is directed at some other agent, so, in effect, S acts without consent. The point is that there is no valid consent for that

\footnotetext{
${ }^{10}$ Sections 2-4 of this article address, in order, the three arguments that Dougherty refers to as: the argument against sexual moralism; the argument from a substantive account of consent; the argument from the case of the Chihuahua.
} 
agent to do what he did (there would have been consent for $T$ to have sex with $\mathrm{R}$ had $\mathrm{T}$ been the person present rather than S). This is a scope-based explanation of the deceptive undermining of consent.

A scope-based account of the deceptive undermining of consent is at the root of Dougherty's expansionist argument. In fact, there are two lines of argument here: one rests upon a substantive (but flawed) theory of the normative scope of consent, plus a second one (also flawed) that does not. We will consider each in turn.

The 'substantive' argument begins with an appeal to the Intentions Thesis: 'The rights that we waive are the rights that we intend to waive' (736). This is plausible. However, it is not the Intentions Thesis verbatim that does the work against the Lenient Thesis, but, rather, a more specific assumption about the way that the consentor's intentions fix the normative scope of consent. Dougherty correctly claims:

In consenting, we intend to allow a restricted range of possibilities, where these restrictions are both implicit and explicit. Any actual interaction with our persons or property is consensual only if this interaction falls within this restricted range of permitted possibilities.' (736)

Dougherty then adds something that has the ring of truth, but on closer inspection is less clear:

On this account of consent, if we object to events in virtue of any feature of them, then they lie outside the restricted range of possibilities to which we are consenting. (736) 
One interpretation of this is framed with indicative conditionals: if we object to $\mathrm{S}$ doing $\mathrm{X}$, then we do not intend to permit $\mathrm{S}$ to do $\mathrm{X}$ by our consent. This claim is not true. We can, of course, object to some feature of S's doing X, but, all things considered, still consent to it. For example, R may very much object to her boorish boss, and not at all want the boss to enter her home, but, for a wide range of other reasons she still decides to permit her boss to enter her home. However, Dougherty makes a second assumption about consent framed in terms of knowledge-involving counterfactual conditionals: 'were we aware of any of the features of the event, we would have to still be happy to go along with it' (emphasis added, 736).

However, contra Dougherty, such a counterfactual cannot be a necessary condition for valid consent. There is nothing incoherent about the idea of valid consent that we regret with the benefit of hindsight (and hindsight is simply a temporally delayed parallel to the counterfactuals cited above). In such cases our consent does render others' actions permissible even though we would not have consented had we known of the relevant fact. For example, suppose $\mathrm{R}$ is happy to have casual sex with many people but she also has a romantic ideal that when she meets "the one" she will have a long courtship, rather than "jumping into bed". At a party $\mathrm{R}$ has casual sex with $\mathrm{S}$ judging him, at that moment to be "film-star handsome, but probably shallow, good for a one-night stand". After some more dates, however, she comes to recognise that $S$ has the traits that make him a very good candidate for being "the one". Had she known that he had these traits she would not have consented on that occasion; she would have "saved it for later". She regrets consenting when she did. However, if Dougherty's theory is correct then $\mathrm{S}$ wrongs $\mathrm{R}$ in the same way he would were he to have sex with her whilst she was unwilling and comatose-though blamelessly - and this is because $\mathrm{R}$ would not have consented on that occasion, had she 
known these facts about $S{ }^{11}$ It is no good for Dougherty to reply that these examples are about kinds of fact that are nothing to do with the sexual encounter (and, as such, can be of no relevance to determining the scope of consent): Dougherty claims that ignorance of facts about an agent's age, income, education, or about ' one's attitudes toward pets, or even how funny one finds the other person' (719) can invalidate consent, so facts about S's personal traits of character readily fall within the scope of his account.

Dougherty argues that this way of thinking about the normative scope of consent - that the scope of what we permit by our consent to is fixed, in part, by what we would consent to with full relevant knowledge-is grounded in the idea that the normative force of sexual consent is importantly bound up with the significance of autonomy. But most (modern, liberal) theorists of sexual consent agree about the normative significance of our sexual choices without endorsing the expansionist conclusion. Sexual consent operates against a backdrop of first-order claim rights against certain kinds of bodily touching by others. In liberal sexual ethics individuals possess a distinctive kind of discretionary normative power to create exceptions to those rights. It is up to $R$ whether to consent, and to whom to give consent, and for what. R may decide on a whim, or for reasons that others find foolish. The discretionary power to permit is protected by further normative elements, including obligations upon other parties to refrain from interfering in the exercise of that power. Framed thus, this kind of radically discretionary individual power underpins a distinctive and significant kind of individual 'sovereignty' and control in our sexual relationships with others.

Dougherty's appeal to knowledge-involving counterfactuals about what we would consent to were we to have full knowledge is a reflection of his commitment to something that goes way

\footnotetext{
${ }^{11}$ Dougherty is clear that, on his view, the facts that invalidate consent are distinct from the facts that determine blameworthiness. He gives an example of Candace asking to store her skis on Courtney's property, both are unaware that the skis belonged to Stalin. Courtney would not have agreed had she known. On Dougherty's view there is no valid consent, Candace wrongs Courtney, but blamelessly so (738).
} 
beyond the recognition of the fact that valid consent must be properly voluntary. Dougherty seems to favour some kind of "ideal autonomy" conception of the power to permit by consent, one that holds that we permit only those things that we would choose to permit were we to be appraised of all relevant facts. The fact that consent decisions are ours to make, and that others ought not to unduly influence them, does not entail that we do not permit $\mathrm{S}$ to do $\mathrm{X}$ if we would not consent were we to be appraised of all the facts about that action or the agent performing it. Dougherty does not provide any argument for this kind of 'ideal autonomy' grounding of the power to permit by consent and, with a more modest and plausible conception of what is involved in possessing a discretionary normative power, the expansionist argument is unsupported.

\section{Scope-based argument 2: analogy and extension}

Suppose we reject Dougherty's theory of the normative scope of consent. He could still argue that examples of seemingly "minor" deception are structurally analogous to examples like that of impersonation and, as such, if we accept that partner impersonation invalidates consent so too will, say, deception about character traits or educational background. In partner impersonation consent is directed at - and only at-one particular individual, but another individual performs the act. But acts of consent are not merely directed at individual agents, they can be directed at types of action, and actions, like agents, can be concealed. For example, suppose $\mathrm{S}$ is a male gynaecologist. $\mathrm{S}$ tells patient $\mathrm{R}$ that he needs to perform an internal examination by inserting a speculum. R consents to the examination. With R's viewpoint blocked by a screen, $\mathrm{S}$ inserts his penis. ${ }^{12}$ Here consent is given to a type of act,

\footnotetext{
${ }^{12}$ McNair v. Nevada, 108 Nev. 53, 825 P.2d 571 (1992). See Rollin M. Perkins, Perkins on Criminal Law, 1st ed. (New York: Foundation Press, 1957), p. 857.
} 
but another type of act is performed. ${ }^{13}$ Here it does not matter whether $\mathrm{R}$ would have consented with ideal knowledge, the point is that she didn't consent to that. These two examples reflect two broader schemata for normatively deficient consent transactions:

(i) PARTICULAR AGENT: R consents (only) to $S$ doing F, but $T$ does F

(ii) TYPE OF ACT: R consents (only) to $\mathrm{S}$ doing $F$ but $\mathrm{S}$ does $G$.

Now consider the supposedly 'minor' dealbreaker cases, such as deception about one's educational history. This seems to involve a third schema, a variant upon the first two:

(iii) TYPE OF AGENT: R consents (only) to an agent of type $X$ doing F, but an agent who is not $X$ does $\mathrm{F}$.

As an example of (iii), suppose R consents to surgery; she does not specify which surgeon will perform the act, but her consent is restricted in scope to appropriate medical personnel: agents of a certain type. If an unqualified anaesthetist "has a go" at surgery whilst $\mathrm{R}$ is unconscious, $\mathrm{R}$ is wronged, because consent was only directed at agents of a certain type, so no permission is given to agents who are not of that requisite type. But if we allow that transactions of type (iii) involve no permission for the act that is performed (by that agent) we seem to have reached Dougherty's expansionist conclusion. Here are two further instances of (iii):

(iii a) $\mathrm{R}$ consents (only) to a person who went to Harvard touching her body, but an agent who did not go to Harvard does so.

(iii b) $\mathrm{R}$ consents (only) to a person who is rich touching her body, but an agent who is not rich does so.

\footnotetext{
${ }^{13}$ Elsewhere 'Why Deception Does not Undermine Consent' (under review) I discuss why and when this kind of deceptive strategy arises and the importance of the concealed act being evidentially similar to the type of act for which consent is sought.
} 
The line of argument developed above presupposes that schema (iii) has an application in the case of everyday sexual consent. But sexual consent is, typically, unlike consent to surgery: it is not directed at types of agent, it is directed at a unique particular agent. As a simple test, we need only consider whether any agent, other than the one who did the act would have been permitted to act. In the 'surgery' case the answer is yes: another surgeon could have acted permissibly, because the consent was directed at any member of a set. But when $\mathrm{R}$ consents to sex with $\mathrm{S}$ on the assumption that $\mathrm{S}$ went to Harvard, consent is certainly not directed at any person who went to Harvard. Consent directed at a particular person is not simply a narrower version - a limit case — of consent directed at anyone of a certain type.

Consider a simple non-sexual example: $\mathrm{R}$ has some good quality old winter clothes to dispose of. She puts up a sign saying "Free clothes for the homeless" in her yard. Suppose S is not homeless, but takes the clothes. This is an instance of schema (iii) above: S wrongs R, as R's consent was directed at a type of person and $\mathrm{S}$ is not of that type. But now suppose $\mathrm{R}$ often sees S late at night wandering the streets looking unkempt and underdressed for the weather. She learns that $\mathrm{S}$ is called Bob. Assuming him to be homeless, she leaves a package of clothes out in the street clearly labelled "Bob, these are for you, help yourself". Bob is not homeless. He is a well paid professor of logic whose attentions are focused on matters other than his appearance. Bob sees the note and being poor at reading people's intentions can't work out why he is being offered clothes, but there is a clear message that they are for him, so he takes them. ${ }^{14}$ Here $\mathrm{R}$ consents to $S$ 's taking the clothes on the assumption that $\mathrm{S}$ is homeless (and it is not directed at any member of a set). The consent is directed at a particular agent, but based upon a false assumption about his properties. It is not the case, in this example, that Bob wrongs R, or that R's consent is invalid. This is true even though R's consent was made on a false assumption and she would not have left the clothes for him had

\footnotetext{
${ }^{14}$ Note that on the 'ideal autonomy' theory, Bob wrongs $\mathrm{R}$ in the same way that he would were he to have stolen them because $\mathrm{R}$ would not intend to give Bob the clothes had she known he was a well-paid logician.
} 
she known he was a well-paid logician. On Dougherty's account of the normative scope of consent, by way of contrast, Bob does wrong $\mathrm{R}$ and there is no consent for his taking the clothes. This is because Dougherty's account does not acknowledge the difference between

(i) intending to permit $\mathrm{S}$ to do $\mathrm{X}$ on the (false) assumption that $\mathrm{S}$ is $\mathrm{F}$;

and

(ii) intending to permit anyone who is F (but only those who are F) to do X.

On Dougherty's account $\mathrm{R}$ does not intend to permit a non-homeless person to take the clothes, and, as such, the fact that Bob is not homeless implies that no valid consent was given for him to do so. In short, the fact that there are instances where consent fails to permit another's actions for 'scope-based' reasons (as in our three schemata above) does not imply that the Lenient Thesis is false. This is because sexual consent is directed at particular individuals based upon assumptions that we make about their features it is (typically) not directed at members of a set who have those features.

\section{Conclusion}

The aim here has been to resist a certain kind of 'expansionist' account of deceptive wronging in sexual consent, one that would vastly increase the amount of (and the moral seriousness of) a great deal of deception in the context of (what seem to be) consensual sexual relations. First, Dougherty's arguments against the "gradable voluntariness" account fail-especially because of a failure to recognise or acknowledge that dealbreakers themselves can be "graded". Although the gradable voluntariness theory does not directly entail the Lenient Thesis, it does lend support to certain variants of it. The gradable voluntariness theory does not imply an objective distinction between "peripheral" and "core" features of a sexual actwhere deception about the "peripheral" features leaves consent valid, whilst deception about 
"core"' features does not. A subjective variant of the Lenient Thesis can be viewed as holding that certain kinds of fact will tend to be of less deliberative importance than others. When this line of thought is combined with the line of argument that only deception involving strong dealbreakers invalidates consent we have both an explanation of, and a limited justification of the Lenient Thesis. The justification is a limited one because on this line of argument if some fact is a strong dealbreaker for the consentor, then, in principle, consent may be invalidated (if the degree of undue influence upon the consentor's decision is above a certain threshold. Dougherty's theory does not allow for any distinction within the class of dealbreakers, so, on his account, any dealbreaker no matter how weak, counterfactually speaking, invalidates consent.

We then identified a further 'driver' of expansion in Dougherty's view that the normative scope of consent is fixed by what the consentor would consent to, given ideal knowledge about the agent and act. This 'ideal autonomy' theory was without support. We then saw that we can argue for the expansionist conclusion without a commitment to a theory of the scope of consent grounded in ideal autonomy theory. In some contexts, ignorance of a person's traits can undermine consent in the same way that consent is undermined in the impersonation case. A person who consents to being operated on by a surgeon (and only a surgeon) is wronged if a non-surgeon does so: no consent was given for a person of that kind to the act. But there are important differences between giving permission to a particular individual on the assumption that they are $\mathrm{G}$, and directing one's consent at anyone who is $\mathrm{G}$. If we fail to keep apart permitting an individual and permitting a type of person, to do $\mathrm{X}$, then we risk collapsing the kind of normative failing we find in cases of partner impersonation (where consent is directed at a unique individual and not at the person who performs the act), and cases where the consentor would not have consented had she known of some fact about the other agent. 
In sum, then, the expansionist conclusion proposed by Dougherty is not justified by the arguments that Dougherty offers. Dougherty's negative arguments, targeting the gradable voluntariness theory, leave the "subjective" variant of the Lenient Thesis standing. Dougherty's positive arguments, insofar as they rest upon an overly strong conception of autonomy, and upon a lack of clarity about the distinction between permitting an individual to do a type of act and permitting a type of individual to do it, leave both the "subjective" and "objective" variants of the Lenient Thesis standing. However, we have not shown here that a rejection of the Lenient Thesis might not be justified by some other line of argument. ${ }^{15} \mathrm{~A}$ revision to our intuitions about the range of, and seriousness of, wrongings attendant upon deceiving into sex may be justified, but further work needs to be done to show conclusively that this is the case. The aim here has been more modest - and largely negative - to show that we should not think about the deceptive undermining of consent in the way that Dougherty suggests.

\footnotetext{
${ }^{15}$ Relatedly, although we have defended the 'gradable voluntariness' theory from Dougherty's objections to it we have not shown that it is an adequate account of how deception undermines the normative force of consent. Elsewhere I offer an account of the normative implications of deception for certain kinds of consent transaction (more specifically, examples of partner impersonation or of performing a sexual act in the guise of a medical examination). This account overlaps with Dougherty's to some extent, in that the explanation of the wronging in these examples is framed in terms of an act being performed that falls outside the normative scope of consent. It is also argued — unlike Dougherty's account (and unlike the 'graded voluntariness' account) — what the consentor would have decided, had she not been deceived, is not of direct normative relevance ('Why Deception Does not Undermine Consent' (under review)).
} 